\title{
Marked differences in redox status of professional soccer players depending on training types
}

\author{
Andrea Bolner ${ }^{1}$, Carlo Berizzi², Sujem Benedetto ${ }^{3}$, Roberto Vano ${ }^{3}$, Rocco Micciolo ${ }^{4}$, Andrea Muscarà5 ${ }^{5}$ Aldo Passelli ${ }^{6}$, \\ Ottavio Bosello7, Giampietro Nordera ${ }^{1}$ \\ ${ }^{1}$ Oxidative Stress Center (CSOx), Vicenza, Italy \\ ${ }^{2}$ Nutrivector $^{\circledR}$, Mogliano Veneto, Treviso, Italy \\ ${ }^{3}$ Alagen-io, Promos Biotech, Udine, Italy \\ ${ }^{4}$ Department of Psichology and Cognitive Sciences, University of Trento, Trento, Italy \\ ${ }^{5}$ Friuli Coram Srl, Udine, Italy \\ ${ }^{6}$ Udinese Calcio, Udine, Italy \\ ${ }^{7}$ Department of Medicine, University of Verona, Verona, Italy
}

\section{ABSTRACT}

Objective: An intense physical activity cause inflammation and produces oxidizing molecules that physiologically "train" the body to restoring the homeostatic balance. It's alteration can lead to a sub-clinical pro-inflammatory state known as "oxinflammation." The aim of this study was to measure some inflammation and redox biomarkers in a team of soccer players during a competitive season to identify relationships between oxinflammation, nutrition, workloads, and athletic performances.

Methods: Thirty four players were evaluated every 2 months from pre- until end-season (visits V0-V4). At each time, a panel of oxinflammatory biomarkers were measured: interleukin-6, high-sensitivity C-reactive protein (hsCRP), total peroxides (derivates of Reactive Oxigen Metabolites), total antioxidant barrier (biological antioxidant potential ), total (GSSG + GSH) and reduced (GSH) glutathione, vitamins A and E, beta carotene, lycopene, coenzyme Q10, 3-nitrotyrosine (3-NT) and 8-hydroxy-deoxyguanosine. The nutritional program was customized for each athlete to ensure adequate supply of micro- and macro-nutrients. Starting from V2, following the replacement of the coach, the training program was suddenly changed, and the high intensity work was significantly increased. Results: Until V2, the oxinflammation balance remained still in equilibrium, and total and reduced glutathione were favorably increased $(+19 \%$ and $+16 \%$ vs. V1, respectively, $p<0.001$ ). After the change of workloads, the inflammation had worsened decreasing GSH and sharply increasing 3-NT, marker of irreversible nitration (+ $1274 \%$ at $\mathrm{V} 4, p<0.001$ ).

Conclusion: Above a threshold, the eccentric exercise has altered the oxinflammatory balance. The nutritional intervention was partially able to counteract the alteration but, the worsening of balance at the end of season, showed that probably, it was much more conditioned by the physical overload. A customized balancing between training, rest period, and nutrition is, therefore, crucial, and the measurement of some oxinflammation markers, as hsCRP, GSH, and 3-NT, may be helpful to evaluate the state of fitness and recognize early the approaching of the over-training threshold.

\section{ARTICLE HISTORY}

Received May 12, 2019

Accepted November 08, 2019

Published November 27, 2019

\section{KEYWORDS}

Oxidative stress markers; inflammation; $\mathrm{T} / \mathrm{C}$ ratio; nutrition; high-intensity training

\section{Introduction}

Intense physical activity causes inflammation and produces oxygen (ROS) and nitrogen (RNS) reactive species, that physiologically "train" the body to a counter-regulatory response aimed at restoring the homeostatic equilibrium [1-5]. This feedback

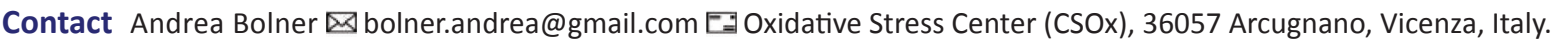

(C) 2019 The Authors. This is an open access article under the terms of the Creative Commons Attribution NonCommercial ShareAlike 4.0 (https://creativecommons.org/licenses/by-nc-sa/4.0/). 
results from a complex network of redox reactions, second messengers, and epigenetic modulators whose altered function can lead the stabilization of a chronic inflammatory state [6-12]. This condition is followed by the establishment of vicious circles in which a persistent pro-oxidant environment triggers a systemic sub-clinical pro-inflammatory state named "oxinflammation" [13-16].

In sports, the oxinflammation has been associated with the over-training, a condition implicated, in the short term, in the impairment of athletic performances and, in the medium to long term, in the triggering of metabolic disorders and other dysfunctions [17-22].

The aim of our study was to measure the biochemical modifications of the oxinflammatory balance in a team of soccer players who, by profession, are subjected to high loads of muscular activity and, therefore, of pro-oxidant stimulation. During a competitive season, we have, therefore, measured a panel of inflammation and redox-balance biomarkers that had already been shown significant in sport $[23,24]$.

Since physical activity and nutrition affect directly the homeostasis, the first because potentially involved in the activation of ox-inflammatory process $[25,26]$, and the second for its incidence on the composition and efficacy of the antioxidant barrier [27-33], the muscular workloads and the nutritional intakes of the athletes were also measured. While the training loads were defined independently by coach and his staff, as often unfortunately happens even in professional teams, our nutritionists followed the athletes in order to define appropriate nutritional supplies. We wanted in this way evaluate whether a careful nutritional control, customized for each athlete on the basis of biochemical and physio-metabolic data, could allow, on its own, to maintain the oxinflammatory balance and to correct or, if possible, prevent dangerous imbalance conditions.

\section{Methods}

Thirty four professional players of a soccer team playing in the Italian A series championship were monitored during the competitive season 2017-18; their age was $24.9 \pm 5.2$ (mean \pm SD). Each player was evaluated at the end of the pre-season period (V0) and after every 2 months (V1-V4 visits) until the end of the championship, according to the timing suggested by the Italian Football Federation (FIGC). Many tests performed were those recommended by the FIGC protocols for medical monitoring of football players. Before each visit, the athletes subscribed the informed consent for personal data treatment in accordance with the General Data Protection Regulation.

\section{Biological samples}

Blood samples were collected at rest, 48 hours after the last match, in vacuum sealed tubes with ethylenediaminetetraacetic acid (EDTA), sodium citrate or without, as required by the analytical methods. After sampling, the tubes were immediately centrifuged at $3,500 \mathrm{rpm}$ for 10 at $4^{\circ} \mathrm{C}$ and plasma or serum samples were frozen at $-80^{\circ} \mathrm{C}$ until analysis. First morning spot urine samples were also collected and frozen.

\section{Lab tests}

A large panel of blood routine tests was analyzed to evaluate the muscle damage, the hemopoietic, hepatic, renal and thyroid functions, and the glucose, lipid, protein, and iron metabolisms. The anabolic index was measured as ratio between testosterone and morning cortisol (T/C), as previously reported [34]. All the routine tests were performed on Beckman Coulter analyzers. By gas chromatography and mass spectrometry, the lipidomic profiles of the erythrocytes or red blood cells (RBC) membranes were determined to quantify the most relevant saturated (SFA), mono-unsatured (MUFA), and poly-unsatured fatty acids (PUFA) [35].

The oxinflammation state was evaluated with some plasmatic markers: interleukin-6 (IL-6), high-sensitivity C-reactive protein (hsCRP), total peroxides derivates of Reactive Oxigen Metabolites (dROMs), total antioxidant barrier [biological antioxidant potential (BAP)], total (GSH+GSSG) and reduced (GSH) glutathione, and coenzyme Q10, as components of the antioxidant endogenous barrier, vitamins $\mathrm{A}, \mathrm{E}$, beta carotene, and lycopene, as components of the antioxidant exogenous barrier, and 3-nitrotyrosine (3-NT), marker of irreversible nitration. Total and reduced glutathione were analyzed in EDTA whole blood by high-performance liquid chromatography (HPLC) and fluorometric detection, using a kit from Eureka Lab Division (Chiaravalle, Italy); the measure of oxidized form (GSSG) was obtained by difference between total (GSSG + GSH) and reduced (GSH) glutathione. Coenzyme Q10, vitamin A, vitamin E, beta-carotene, lycopene, and 3-NT were analyzed in plasma by HPLC and UV detection, always using Eureka commercial kits. The marker of oxidative damage on nucleobases, 8-hydroxy-deoxyguanosine (8-OHdG), was measured in urines with a HPLC method and electrochemical detection, as previously reported [36]. 
The Gilson HPLC system, controlled by Unipoint software, consisted of two pumps (models 306 and 307 ), and a 234 autosampler; the columns and the mobile phases are those provided with the kits. The detections were performed with 875 UV photometer and 1520 fluorometer Jasco and with electrochemical detector Coulochem II ESA, fitted with a model 5011 high-sensitivity cell.

The oxidizing capacity of plasma, understood as total content of peroxides (dROMs), and the BAP, understood as total content of antioxidant species, were determined with two colorimetric end-point assays from Diacron (Grosseto, Italy) and a microplate ELX-800 spectrophotometer (Biohit).

\section{Hydratation status}

Since its association with the redox balance $[37,38]$, the total body water was estimated at rest, 48 hours after the match, using Bioelectrical Impedance Analysis (BIA), taking into account the sensitivity to osmolarity $[39,40]$. The whole body resistance and reactance were also measured with a $50 \mathrm{kHz}$ single frequency, phase-sensitive BIA-101 device (RJL/ Akern Systems, Florence, Italy) [41].

\section{Nutritional intervention}

The hydration and body weight data were measured principally in order to increase the athlete's awareness in fluid intake, in relation to own physiology and biochemistry that influence energy substrates consumption and sweat losses. The nutritionists suggested, therefore, to drink not less than 1.5-2 $\mathrm{l}$ of water daily and a glass (200-250 ml) of fresh fruit and vegetable juices just before lunch [42].

After V0, nutrition was individually structured to ensure, at each athlete, an adequate supply of macronutrients, in relation to own eating habits and energy expenditure. The resting metabolic rate (RMR) was calculated as previously reported from Ravussin et al. [43], where the fat free mass was estimated using BIA as reported from Lukaski et al. [44]. The approximate total energy expenditure (TEE) was calculated using the formula TEE $=\mathrm{RMR} \times \mathrm{PAL}$, where the physical activity level (PAL), was set at 1.8 as recently reported by Brinkmans et al. [45].

The intake of fruit and vegetables was also customized, in order to prevent deficiencies of micronutrients and exogenous antioxidants, according to the recommendations of Italian Society of Human Nutrition. To increase the compliance, the nutritionists have personally coordinated the catering service and attended almost all the breakfasts and lunches consumed by the athletes. At the occurrence of sub-optimal conditions, highlighted by the biochemical and lipidomic profiles, the feeding was integrated with micronutrients (vitamins, minerals, and coenzyme Q10 in nutritional doses) and specific PUFAs (flax seeds oil, borage oil, and docosahexaenoic acid, DHA) in attempt to correct the imbalances and improve SFA/MUFA and omega-3/ omega- 6 ratios.

Starting from V3, during each training session, athletes began to drink at least $0.5 \mathrm{l}$ of water with added carbohydrates (a 5\% solution of maltodextrins), in order to promote recovery of muscle glycogen stores during post-exercise period [46].

\section{Training load}

For all the championship, coaches and their staff have established the workloads in a completely autonomous way. During the outdoor training sessions, a player tracking technology (18-Hz, GPEXE LT, Exelio, Udine, Italy) was used to quantify the muscular activity, with particular attention to the number of accelerations above $3 \mathrm{~m} \cdot \mathrm{s}^{-2}$ as an estimation of high intensity work [47]. These data were after evaluated with retrospective analysis in order to calculate the averages of weekly runs distances (speed $\geq 8 \mathrm{~km} \cdot \mathrm{h}^{-1}$ ) and accelerations number, expressed as percentage respect to the data of a typical Italian official match, as reported from Osgnach et al. [48].

\section{Statistical analysis and calculations}

The data were processed to obtain means, standard deviation (SD), and graphical summaries. The measurements at the beginning of the competitive season (V1) were considered as baselines: with respect to them, the percentage variations of each biomarker were calculated for visits from V2 to V4 and plots of the relative deviations from baseline were reported. To compare the visits in pairs, the data were corrected for non-sphericity and elaborated with Tukey's honestly significant difference test. The processing was performed with STATA program (version 13.1) and the significant level was fixed at $5 \%$ ( $p$-value $<0.05$ ).

The deviations of biomarkers from baseline were also evaluated by comparison with the respective critical delta values (CDVs), calculated for each marker from biological and analytical variabilities measured at visits V0 and V1, according to Fraser and Harris [49-51].

The redox potential of the pair GSH-GSSG (EnLev) and the estimated activity of glutathione reductase (Gred Index) were calculated with the Nernst equation $[52,53]$. 


\section{Results}

Few days before V2, due to unexpected choices of the sports club, the team coach has been replaced by a second, who has drastically modified the training program followed during the first in-season period, with a remarkable increase of the high-intensity work. The averages of weekly run distances and the number of accelerations with the first coach were, respectively, $140 \%$ and $173 \%$ respect to a typical Italian official match; with the second coach, the run distances remained almost unchanged (146\%) but the accelerations were much increased (246\%).

The pre-season analysis of RBC membrane fatty acids showed an altered omega-3 index, mainly due to a deficit of DHA and an excess of arachidonic acid (ARA). Indeed, 16 out of 34 athletes showed DHA's values lower, and 23 showed ARA's values higher than the optimal ranges. The nutritional intake of omega-3 was consequently modified starting from V1 with a weekly increase in fish consumption and food supplements, particularly flaxseed oil and DHA. At the follow-up in V2, this resulted in a mild increase of DHA and, even if to a lesser degree, in a decrease of arachidonic acid (data not shown). The dehydration levels during the championship have remained almost unchanged, exceeding of $1 \%$ body weight in three athletes only.

Among the analytes of the routine biochemical pattern, some were almost always decreased in visits V2-V4 compared to V1 (Table 1): uric acid, adrenocorticotropin (ACTH), hemoglobin, RBC, ferritin, iron, phosphates, calcium, leukocytes, and platelets. Other parameters were instead almost increased: alkaline phosphatase (ALP), alanine aminotransferase (ALT), aspartate aminotransferase (AST), insulin, glucose, cholesterol, sodium. Starting from V2, changes were shown for other parameters: increases for creatine kinase (CPK), lactate dehydrogenase (LDH), folates, magnesium, reticolocytes, sex-hormone binding globulin, thyreotropin (TSH) and decreases for transferrin (TRF), total and saturated, transferrin soluble receptor (srTRF), and thyroid hormones (T3 and T4 free). Because the statistical analysis has demonstrated significative trends for many of these parameters (data not shown), a depth evaluation will be the topic of a next publication.

Variations in the course of season have been highlighted in almost all the markers of the ox-inflammatory pattern (Fig. 1). While with a simple analysis of variance test almost all the variables showed differences between times (the only really not significant was $8-\mathrm{OHdG}$ ), the comparison with
Tukey's test between V2 and V4, each visit in pairs with V1, provided significance for some parameters only (Table 2).

Two months after V1, dROMs were decreased $(-7 \%)$ while BAP was increased $(+12 \%)$, both in a not significant way; instead, statistically significant were the increases of total and reduced glutathione $(+19 \%$ and $+16 \%$, respectively), while the reduced/total ratio was only slightly decreased $(-3 \%)$. Among the other elements of the antioxidant barrier, coenzyme Q10, vitamin A and beta carotene were decreased $(-15 \%,-12 \%$, and $-16 \%)$, while vitamin $\mathrm{E}$ and lycopene were increased (+ $9 \%$ and $+10 \%$ ), not all with statistical significance.

Between the sixth and the eighth month, dROMs increased slightly when compared to V1 ( + $\%$ at V3 and $+8 \%$ at $\mathrm{V} 4$ ) while decreases were observed for total glutathione, reduced and reduced/total ratio, these latter with statistical significance; furthermore, between V3 and V4, the 3-NT has increased exponentially respect to the baseline $(+1274 \%$ at V4); instead, little changes without significance were observed for the urinary levels of 8-OHdG. The hsCRP, that had almost doubled already in V2 $(+92 \%)$, remained high and only weakly decreased at V3 (+45\%) and V4 (+29\%); on the contrary, at the same times, IL- 6 was unchanged or only slightly increased.

The anabolic balance $\mathrm{T} / \mathrm{C}$, almost unchanged between $\mathrm{V} 1$ and $\mathrm{V} 2(+2 \%)$, increased but not significatively at V3 $(+21 \%)$ and returned to initial values at V4 $(+1 \%)$.

The Tukey's test showed significant changes at V3 for BAP, vitamin A, lycopene, GSH, and for the GSH ratio. The increase of 3-NT, already evident in the average values in $\mathrm{V} 3$, has become significant in V4, exceeding also the CDV values calculated at baseline (Fig. 2).

The estimated activity of glutathione reductase (Gred Index) showed always significantly decreases for all the visits after V1. Instead, EnLev was significantly decreased in V3 only and then improved partially towards the end of the regular season. By plotting EnLev as function of the Gred Index it was obtained a map that clearly highlights the variations for the redox pair GSH-GSSG between V2 and V3 (Fig. 3).

\section{Discussion}

Physical activity requires energy, consumes nutrients, and causes inflammation, which is an important source of ROS and RNS. It is well known that, 
Table 1. Descriptive statistics for the routine blood tests performed on the soccer players every two months, from the pre-season visit (V0) to the end of championship (V4). For each analyte, mean \pm standard deviation and relative units are showed.

\begin{tabular}{|c|c|c|c|c|c|c|}
\hline & Units & vo & V1 & V2 & V3 & V4 \\
\hline АСТН & $\mathrm{ng} / \mathrm{l}$ & $44.9 \pm 17.7$ & $28.4 \pm 10.1$ & $28.5 \pm 7.9$ & $35.2 \pm 12.9$ & - \\
\hline Albumin & $\%$ & $64.7 \pm 2.9$ & $64.2 \pm 2.0$ & $65.3 \pm 2.3$ & $65.3 \pm 2.5$ & $64.6 \pm 2.5$ \\
\hline Alpha1 globulins & $\%$ & $3.7 \pm 0.7$ & $3.5 \pm 0.4$ & $3.5 \pm 0.6$ & $3.3 \pm 0.4$ & $3.4 \pm 0.5$ \\
\hline Alpha2 globulins & $\%$ & $8.1 \pm 1.5$ & $8.2 \pm 1.3$ & $7.9 \pm 1.1$ & $7.9 \pm 0.9$ & $8.2 \pm 1.0$ \\
\hline ALP & U/I & $70 \pm 18$ & $78 \pm 21$ & $73 \pm 18$ & $75 \pm 19$ & $71 \pm 19$ \\
\hline ALT & $\mathrm{U} / \mathrm{I}$ & $21 \pm 4$ & $20 \pm 5$ & $23 \pm 8$ & $26 \pm 7$ & $23 \pm 8$ \\
\hline AST & U/I & $29 \pm 8$ & $25 \pm 5$ & $33 \pm 13$ & $33 \pm 11$ & $28 \pm 9$ \\
\hline Beta1 globulins & $\%$ & $5.4 \pm 0.5$ & $5.4 \pm 0.5$ & $5.6 \pm 0.4$ & $5.4 \pm 0.4$ & $5.3 \pm 0.4$ \\
\hline Beta2 globulins & $\%$ & $4.3 \pm 0.6$ & $4.3 \pm 0.6$ & $3.9 \pm 0.6$ & $4.0 \pm 0.7$ & $4.3 \pm 0.6$ \\
\hline Bilirubin, total & $\mathrm{mg} / \mathrm{dl}$ & $0.7 \pm 0.2$ & $0.6 \pm 0.2$ & $0.7 \pm 0.2$ & $0.7 \pm 0.1$ & $0.7 \pm 0.3$ \\
\hline Calcium & $\mathrm{mg} / \mathrm{dl}$ & $9.2 \pm 0.3$ & $9.4 \pm 0.4$ & $9.2 \pm 0.3$ & $8.8 \pm 0.4$ & $9.2 \pm 0.3$ \\
\hline Chloride & $\mathrm{mEq} / \mathrm{l}$ & $101 \pm 2$ & $101 \pm 2$ & $101 \pm 1$ & $101 \pm 1$ & $102 \pm 1$ \\
\hline Cholesterol, total & $\mathrm{mg} / \mathrm{dl}$ & $180 \pm 39$ & $182 \pm 28$ & $182 \pm 32$ & $198 \pm 31$ & $186 \pm 28$ \\
\hline Cholesterol HDL & $\mathrm{mg} / \mathrm{dl}$ & $56 \pm 12$ & $54 \pm 7$ & $59 \pm 12$ & $59 \pm 12$ & $56 \pm 11$ \\
\hline Cholesterol LDL & $\mathrm{mg} / \mathrm{dl}$ & $112 \pm 30$ & $113 \pm 29$ & $112 \pm 27$ & $125 \pm 25$ & $116 \pm 26$ \\
\hline CPK & U/I & $433 \pm 220$ & $316 \pm 126$ & $427 \pm 187$ & $512 \pm 292$ & $381 \pm 180$ \\
\hline Creatinine & $\mathrm{mg} / \mathrm{dl}$ & $1.0 \pm 0.1$ & $1.0 \pm 0.1$ & $1.0 \pm 0.1$ & $1.1 \pm 0.1$ & $1.0 \pm 0.1$ \\
\hline Hemoglobin & $\mathrm{g} / \mathrm{l}$ & $15.0 \pm 0.8$ & $15.2 \pm 1.0$ & $14.8 \pm 0.7$ & $14.9 \pm 0.9$ & $15.0 \pm 1.0$ \\
\hline Eritrocytes & $10^{\wedge} 12 / l$ & $5.1 \pm 0.3$ & $5.2 \pm 0.4$ & $5.0 \pm 0.2$ & $5.1 \pm 0.4$ & $5.1 \pm 0.4$ \\
\hline Ferritin & ug/l & $64.8 \pm 37.7$ & $50.5 \pm 25.8$ & $63.6 \pm 36.8$ & $56.0 \pm 29.0$ & $61.1 \pm 33.9$ \\
\hline Iron & $\mathrm{ug} / \mathrm{dl}$ & $99 \pm 27$ & $92 \pm 30$ & $99 \pm 38$ & $97 \pm 36$ & $81 \pm 22$ \\
\hline Folates & ug/l & $6.6 \pm 1.9$ & $5.4 \pm 1.8$ & $5.7 \pm 1.8$ & $6.3 \pm 2.3$ & $7.5 \pm 2.9$ \\
\hline Gamma globulins & $\%$ & $13.9 \pm 2.3$ & $14.5 \pm 2.3$ & $13.8 \pm 2.7$ & $14.1 \pm 2.6$ & $14.1 \pm 2.5$ \\
\hline GGT & $U / I$ & $22 \pm 4$ & $22 \pm 6$ & $21 \pm 5$ & $23 \pm 7$ & $20 \pm 5$ \\
\hline Glucose & $\mathrm{mg} / \mathrm{dl}$ & $80 \pm 5$ & $82 \pm 9$ & $82 \pm 9$ & $85 \pm 5$ & $83 \pm 6$ \\
\hline Insulin & $\mathrm{mU} / \mathrm{I}$ & $4.3 \pm 1.5$ & $5.3 \pm 3.8$ & $4.5 \pm 1.6$ & $5.1 \pm 1.4$ & $5.3 \pm 2.2$ \\
\hline $\mathrm{LDH}$ & $U / I$ & $341 \pm 64$ & $325 \pm 36$ & $335 \pm 56$ & $358 \pm 57$ & $333 \pm 44$ \\
\hline Leukocytes & $10^{\wedge} 9 / 1$ & $5.4 \pm 1.2$ & $5.8 \pm 1.6$ & $5.2 \pm 0.9$ & $5.3 \pm 1.0$ & $5.1 \pm 0.8$ \\
\hline Magnesium & $\mathrm{mg} / \mathrm{dl}$ & $2.0 \pm 0.1$ & $2.0 \pm 0.1$ & $2.0 \pm 0.2$ & $2.2 \pm 0.2$ & $2.1 \pm 0.2$ \\
\hline Phosphates & $\mathrm{mg} / \mathrm{dl}$ & $4.0 \pm 0.6$ & $3.7 \pm 0.7$ & $3.7 \pm 0.5$ & $3.6 \pm 0.5$ & $3.8 \pm 0.6$ \\
\hline Platelets & $10^{\wedge} 9 / 1$ & $220 \pm 43$ & $211 \pm 43$ & $215 \pm 43$ & $216 \pm 43$ & $217 \pm 39$ \\
\hline Potassium & $\mathrm{mEq} / \mathrm{l}$ & $4.3 \pm 0.4$ & $4.3 \pm 0.3$ & $4.3 \pm 0.3$ & $4.1 \pm 0.2$ & $4.4 \pm 0.2$ \\
\hline Proteins, total & $\mathrm{g} / \mathrm{dl}$ & $7.1 \pm 0.3$ & $7.2 \pm 0.3$ & $7.3 \pm 0.4$ & $6.7 \pm 0.4$ & $7.2 \pm 0.4$ \\
\hline srTRF & $\mathrm{mg} / \mathrm{l}$ & $1.2 \pm 0.3$ & $1.2 \pm 0.3$ & $1.3 \pm 0.3$ & $1.5 \pm 0.4$ & $1.1 \pm 0.3$ \\
\hline Reticulocytes & $\%$ & $1.2 \pm 0.3$ & $1.2 \pm 0.4$ & $1.2 \pm 0.4$ & $1.4 \pm 0.4$ & - \\
\hline S.H.B.G. & $\mathrm{nmol} / \mathrm{l}$ & $36.2 \pm 8.6$ & $36.8 \pm 11.9$ & $35.1 \pm 10.3$ & $38.9 \pm 13.2$ & - \\
\hline Sodium & $\mathrm{mEq} / \mathrm{l}$ & $134 \pm 3$ & $137 \pm 3$ & $141 \pm 3$ & $134 \pm 2$ & $140 \pm 2$ \\
\hline T3 free & $\mathrm{pmol} / \mathrm{l}$ & $5.3 \pm 0.5$ & $5.3 \pm 0.3$ & $5.5 \pm 0.6$ & $5.4 \pm 0.5$ & $5.1 \pm 0.5$ \\
\hline T4 free & $\mathrm{pmol} / \mathrm{l}$ & $10.0 \pm 1.7$ & $10.8 \pm 1.1$ & $11.3 \pm 1.1$ & $10.5 \pm 1.2$ & $10.1 \pm 1.1$ \\
\hline Transferrin & $\mathrm{mg} / \mathrm{dl}$ & $257 \pm 36$ & $253 \pm 34$ & $257 \pm 30$ & $265 \pm 29$ & $237 \pm 27$ \\
\hline Transferrin saturated & $\mathrm{mg} / \mathrm{dl}$ & $74 \pm 19$ & $74 \pm 24$ & $78 \pm 30$ & $80 \pm 29$ & $63 \pm 16$ \\
\hline Triglycerides & $\mathrm{mg} / \mathrm{dl}$ & $62 \pm 20$ & $77 \pm 23$ & $58 \pm 21$ & $72 \pm 32$ & $71 \pm 30$ \\
\hline TSH & $\mathrm{mUI} / \mathrm{l}$ & $2.1 \pm 0.7$ & $1.8 \pm 0.7$ & $1.8 \pm 0.6$ & $2.4 \pm 1.1$ & $2.2 \pm 0.7$ \\
\hline Urea & $\mathrm{mg} / \mathrm{dl}$ & $40 \pm 8$ & $38 \pm 6$ & $38 \pm 7$ & $42 \pm 7$ & $38 \pm 6$ \\
\hline Uric acid & $\mathrm{mg} / \mathrm{dl}$ & $5.9 \pm 1.0$ & $5.3 \pm 1.1$ & $5.3 \pm 0.8$ & $5.2 \pm 0.7$ & $5.2 \pm 0.8$ \\
\hline Vitamin B12 & $\mathrm{ng} / \mathrm{l}$ & $391 \pm 151$ & $435 \pm 137$ & $407 \pm 99$ & $387 \pm 126$ & $386 \pm 115$ \\
\hline Vitamin B6 & ug/l & $35.0 \pm 18.8$ & $22.3 \pm 11.5$ & $24.6 \pm 16.8$ & $31.0 \pm 20.6$ & - \\
\hline Vitamin D & ug/l & $42.6 \pm 14.8$ & $40.3 \pm 12.5$ & $36.6 \pm 5.6$ & $38.3 \pm 8.7$ & $30.2 \pm 5.6$ \\
\hline
\end{tabular}



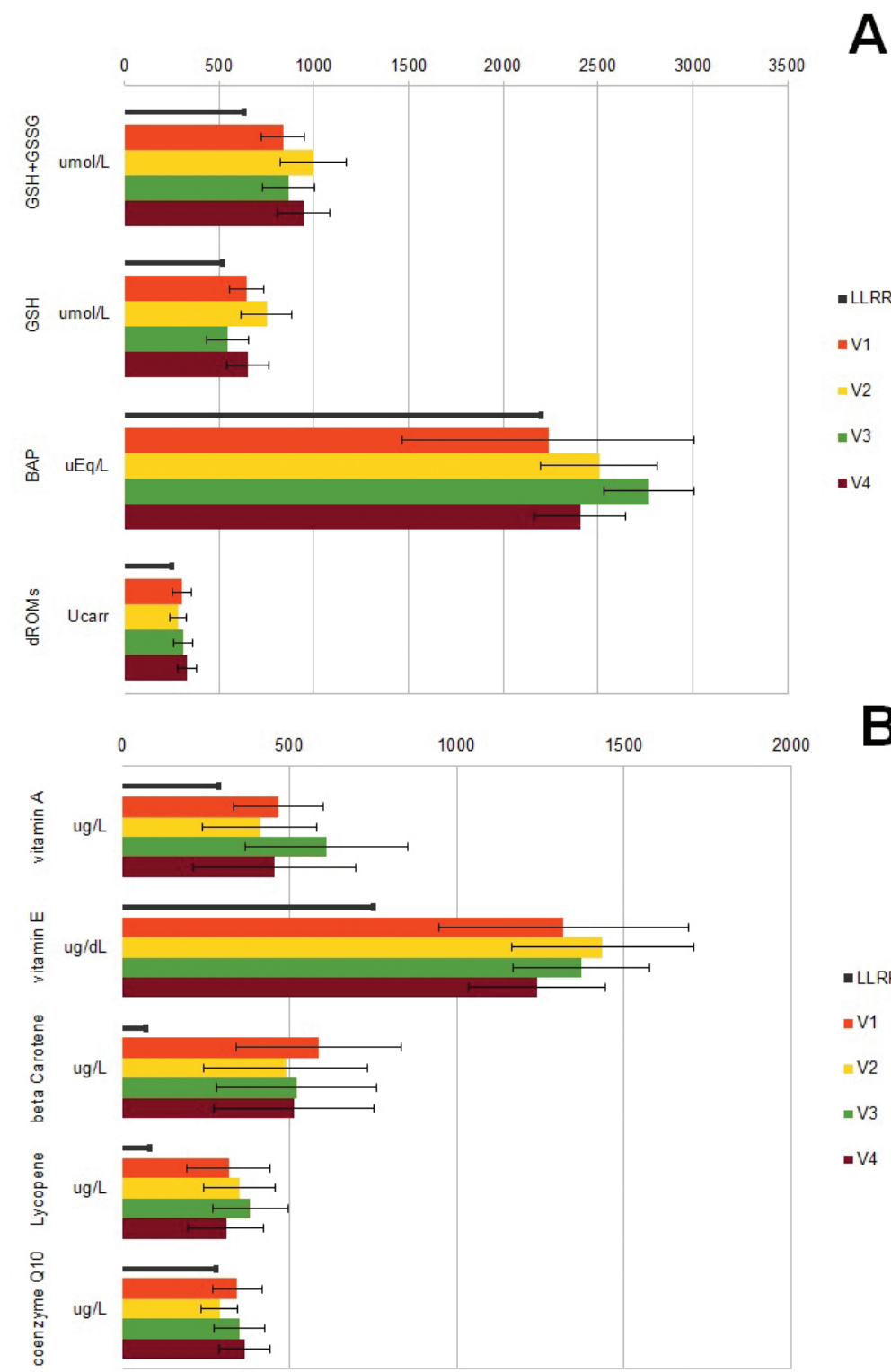

B

- LLRR
=V1
$=\mathrm{V} 2$
$=\mathrm{V} 3$
- V4

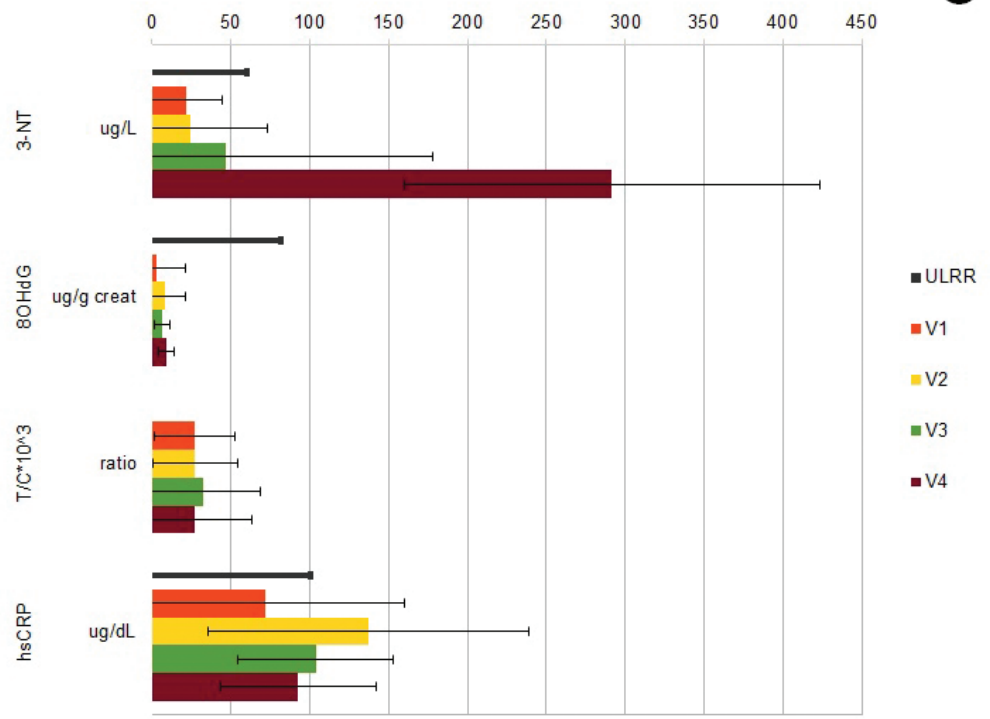

Figure 1. Trends of the oxinflammation biomarkers from V1 to V4: each parameter is reported as relative concentration (mean \pm SD). Since the pathophysiological significance is different for each analyte, in the graphs A and B the black line represents the lower limit (LLRR), and C the upper limit of each reference range (ULRR). 
Table 2. Descriptive statistics for oxinflammatory biomarkers measured from visit V1 to V4. For each marker, mean \pm standard deviations and relative units are reported; the values that were significantly changed versus V1 (Tukey's test, $p<0.001$ ) are marked with asterisk $\left({ }^{*}\right)$.

\begin{tabular}{|c|c|c|c|c|c|}
\hline & Units & V1 & V2 & V3 & V4 \\
\hline GSH+GSSG & umol/l & $838 \pm 138$ & $1,000 \pm 112 *$ & $870 \pm 176$ & $947 \pm 137 *$ \\
\hline GSH & umol/l & $647 \pm 108$ & $752 \pm 90^{*}$ & $546 \pm 134^{*}$ & $656 \pm 111$ \\
\hline GSH ratio & $\%$ & $77 \pm 5$ & $75 \pm 6$ & $63 \pm 9 *$ & $69 \pm 8^{*}$ \\
\hline BAP & $\mathrm{uEq} / \mathrm{l}$ & $2239 \pm 291$ & $2,505 \pm 770$ & $2,770 \pm 307^{*}$ & $2,406 \pm 239$ \\
\hline dROMs & Ucarr & $307 \pm 41$ & $287 \pm 52$ & $312 \pm 44$ & $331 \pm 51$ \\
\hline Q10 & ug/l & $345 \pm 89$ & $292 \pm 73 *$ & $351 \pm 54$ & $368 \pm 76$ \\
\hline Vitamin A & ug/l & $470 \pm 230$ & $410 \pm 130$ & $610 \pm 170^{*}$ & $460 \pm 240$ \\
\hline Vitamin E & $\mathrm{ug} / \mathrm{dl}$ & $1320 \pm 310$ & $1,440 \pm 370$ & $1,370 \pm 270$ & $1,240 \pm 200 *$ \\
\hline beta Carotene & ug/l & $587 \pm 413$ & $490 \pm 247^{*}$ & $522 \pm 244$ & $514 \pm 238$ \\
\hline Lycopene & ug/l & $319 \pm 124$ & $351 \pm 124$ & $384 \pm 108 *$ & $311 \pm 113$ \\
\hline 3-NT & ug/l & $21 \pm 21$ & $24 \pm 24$ & $47 \pm 49$ & $292 \pm 132 *$ \\
\hline $80 \mathrm{HdG}$ & ug/g creat & $3 \pm 1$ & $8 \pm 18$ & $15 \pm 6$ & $16 \pm 7$ \\
\hline $\mathrm{T} / \mathrm{C}^{*} 10^{\wedge} 3$ & Ratio & $28 \pm 8$ & $27 \pm 12$ & $34 \pm 8$ & $28 \pm 7$ \\
\hline hsCRP & $\mathrm{ug} / \mathrm{dl}$ & $72 \pm 103$ & $137 \pm 88^{*}$ & $104 \pm 102$ & $93 \pm 49$ \\
\hline IL-6 & $\mathrm{ng} / \mathrm{l}$ & $2.2 \pm 0.6$ & $2.2 \pm 0.5$ & $2.5 \pm 1.0$ & $2.2 \pm 0.9$ \\
\hline Gred Index & Score & $7.2 \pm 3.0$ & $6.3 \pm 1.5^{*}$ & $3.6 \pm 1.4^{*}$ & $4.6 \pm 1.3^{*}$ \\
\hline EnLevel & Score & $-130 \pm 23$ & $-146 \pm 22$ & $-98 \pm 27^{*}$ & $-124 \pm 24$ \\
\hline
\end{tabular}

these so-called "free radicals," play a key physiological role through the regulation of enzymes involved in the signaling and epigenetic pathways [54,55]. However, the "redox signaling machinery" is an extremely delicate and easily corruptible balance between harms (i.e., inflammation and biological damage) and benefits (i.e., redox signaling and epigenetic control). A long-term sustained production of free radicals could indeed evolve in an oxidative stress which helps to generate permanent losses of the physiological adaptive response, and to stabilizing and reinforcing a chronic pro-inflammatory status.

The combined analysis of some oxidative stress and inflammatory biomarker may aid in monitoring the consistency of the redox balance during muscle exercise and to prevent its alteration.

Particularly, the measurement of dROMs, BAP, and glutathione allowed to evaluate how effective the radicals produced by intense physical exercise, were counterbalanced by the physiological antioxidant barrier. Both GSH ratio and GSH blood concentrations have been already demonstrated associated with oxidative stress in sport [56]. If the acute exercise consumes GSH, increase GSSG and decrease the GSH ratio, a correct chronic exercise may promote both the synthesis and the GSH restoring, enhancing the antioxidant power. However, when the muscle produces radicals above the physiological adaptive capacity, both GSH and its redox potential decreases for greater consumption, and the homeostatic balance becomes altered. Plotting in graph the redox potential (EnLev) and the glutathione reductase activity (Gred), this last estimated from GSSG and GSH concentrations (Fig. 3), it was possible to improve the evidence of these alterations and better understand the events that occurred in vivo. As more negative were the EnLev values and greater was Gred, more the athlete was in homeostatic ox-inflammatory balance and more could be associated to good performances in terms of wins. Instead, as more positive was EnLev and lower Gred, more the athlete was in ox-inflammatory stress and more could be associated to an elevated number of consecutive losses. So, the En Level/Gred Index map could be a tool better than the GSH concentrations only, to evaluate if training load and nutritional support were able to keep or not the athletes in fitness condition.

Regarding the exogenous fraction of the antioxidant barrier, is well known that it depends strictly from the food intakes and supplementations of some micronutrients, such the vitamins A, E, lycopene and beta-carotene, whose concentrations in blood were firstly useful to evaluate its consistency. Furthermore, these measures were necessary because too higher concentrations of antioxidants could excessively extinguish the ROS 

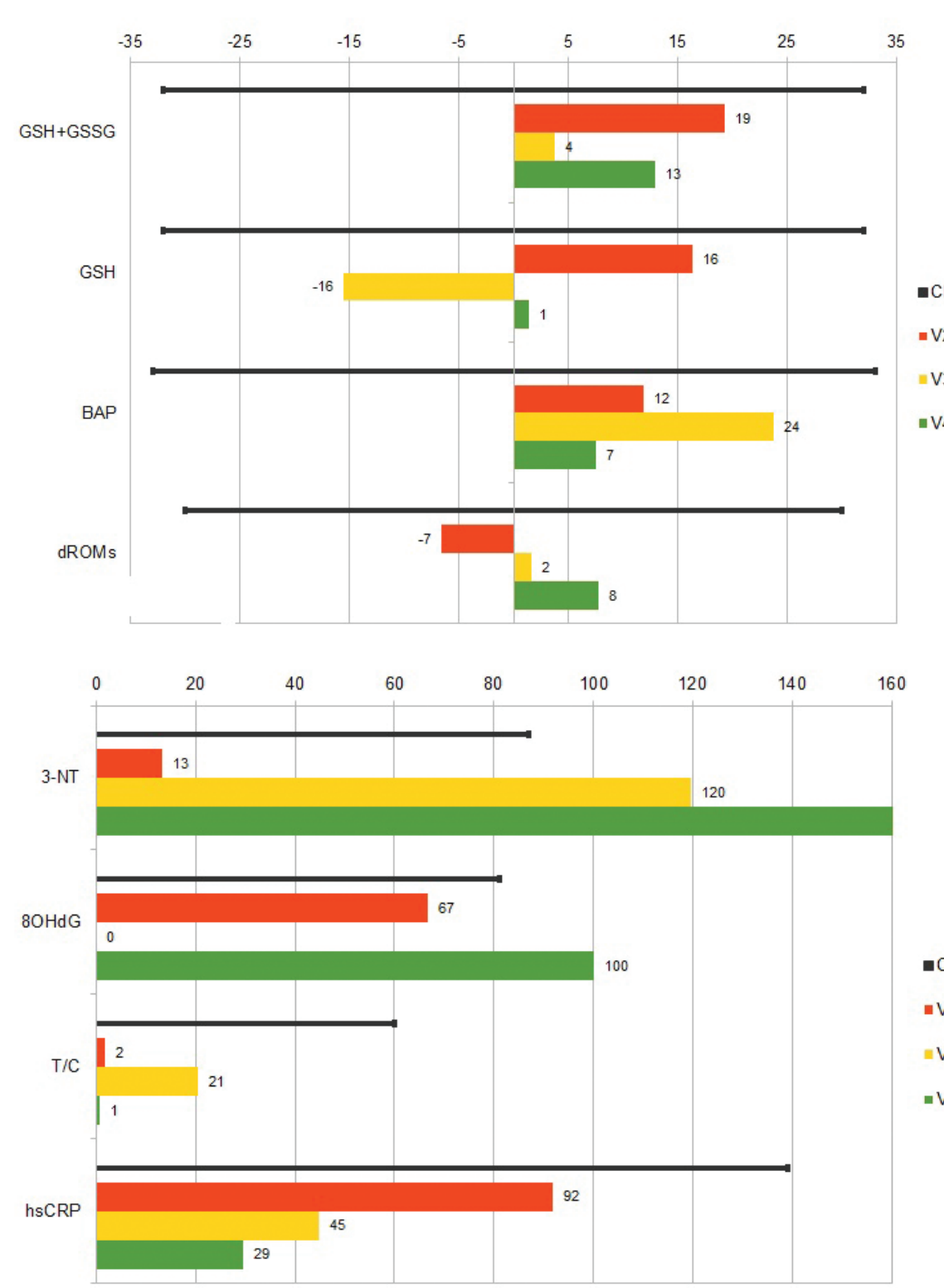

B

-CDV

$-\mathrm{V} 2$

V3

v4

A

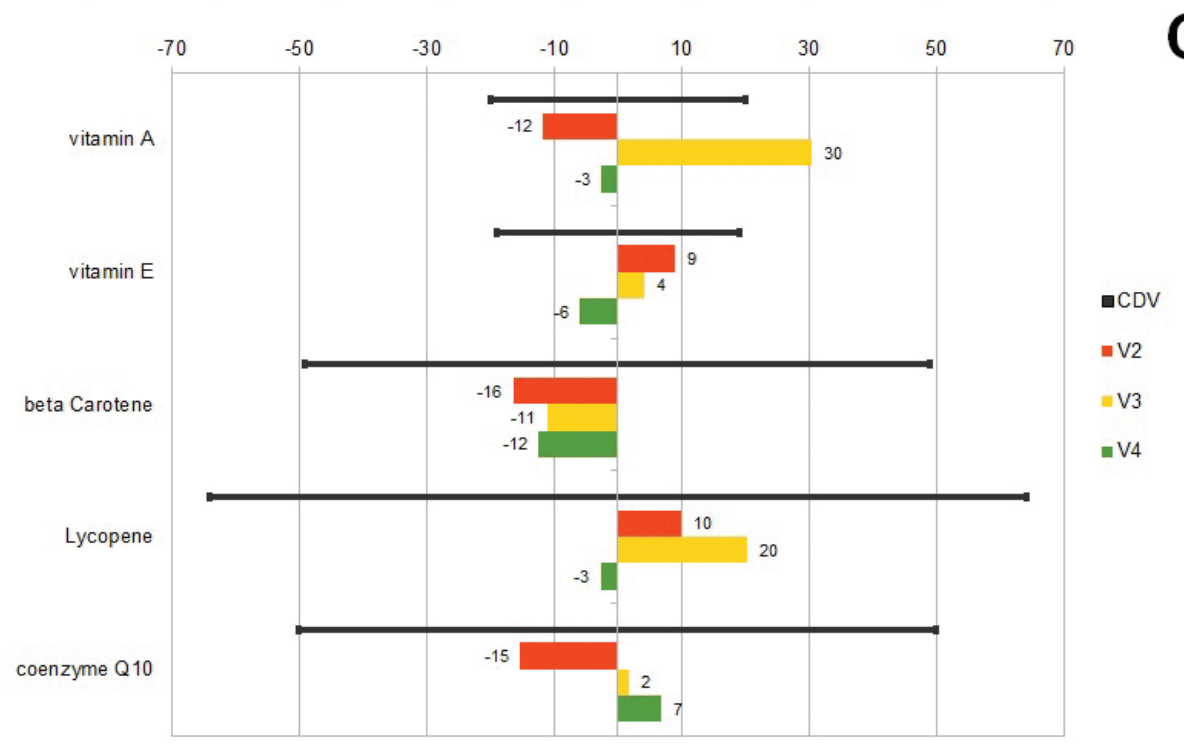

Figure 2. Trends of the redox balance (A), exogenous antioxidant barrier (B), inflammation and oxidative damage biomarkers (C) from visit V2 to V4; the variations for each parameter are reported as percentage of the means vs. V1. The black line represents the critical delta value (CDV) calculated for each parameter in the pre-season visits. 


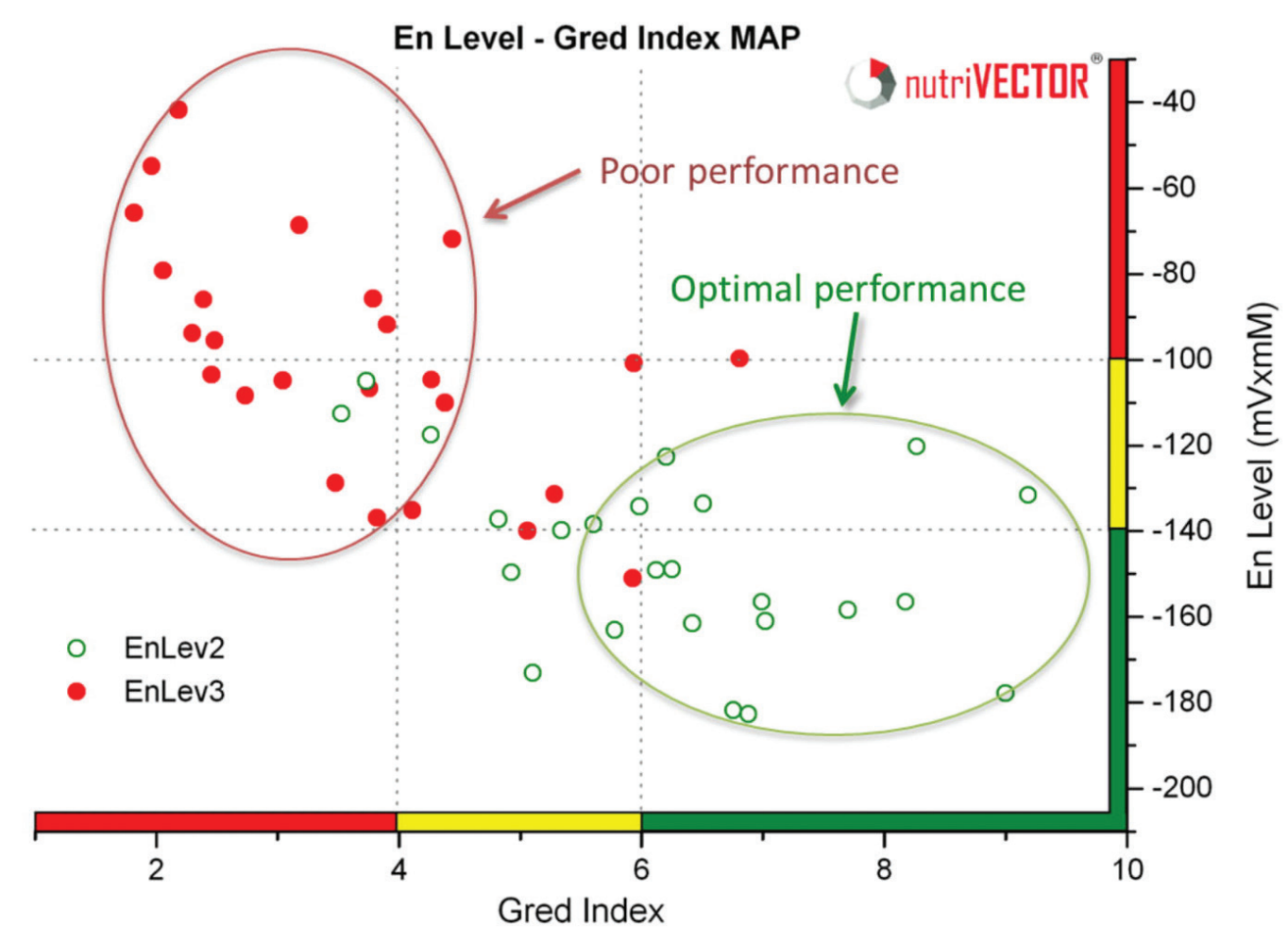

Figure 3. The En Level/Gred Index map: at visit V2, in conditions of equilibrium, the values of the pair GSH-GSSG energy level (EnLev) and of the estimated activity of glutathione reductase (Gred Index) were close to the origin of axes (green circles); instead, in redox imbalance conditions (visit V3), the values moved in the opposite direction (red circles).

and RNS actions, compromising their physiological role. Indeed, excessive supplementations, instead of restoring barrier, risks to alter the redox balance and, in long term, to weaken the physiological capacity of antioxidant response [57-60]. The same was also true for coenzyme Q10 which, although physiologically synthesized, is frequently administered in athletes as dietary supplement: both excess and defective Q10 values could be counterproductive.

Together with the exogenous antioxidant barrier, the pre-season evaluations of the hydration state, biochemical metabolic profile and lipidomic of RBC membrane, allowed a careful assessment of the nutritional status of the athletes.

The success of the customization of the diet according to each athlete nutritional status was demonstrated from the invariance of the hydration conditions of athletes and improvements of the lipidomic profiles of RBC membranes. Particularly regarding lipidomics, it is interesting to highlight that, while the pre-season DHA deficiencies were previously already reported, the excess of arachidonic acid had not been yet emphasized $[61,62]$.

Whit the nutritional program defined after $\mathrm{V} 0$, the ox-inflammatory pattern appeared in substantial equilibrium until V2. Interestingly, between V1 and V2, increases of total antioxidant barrier and of both total and reduced glutathione, and decreases of dROMs were observed although not all with statistical significance. This was an ideal picture of the effects that a correct training and nutrition may have on redox homeostasis. Whit balanced activity and food intake, in fact, the inflammatory insult can be silenced by an already effective antioxidant barrier that can be further enhanced in its endogenous component due to pro-inflammatory and pro-oxidant stimulations induced by training.

Too much activity, however, can lead to conditions in which ROS and RNS consume more antioxidant barrier than they are able to enhance. Once again, a nutritional intervention can help to increase the intake of some nutrients. Whit some feeding integrations, we have so stabilized in V2 the blood concentrations of lycopene and vitamin E: since vitamin A, Q10, and beta carotene were decreasing at this time, the consumption of vitamin A naturally rich foods was improved and a supplementation of Q10 in nutritional doses has been introduced. These interventions have proved effective at the next V3 monitoring with improvements in both these markers (Fig. 2). 
However, after V2 the equilibrium conditions were progressively compromised reasonably for the increase in high intensity training load, which led to the onset of inflammatory conditions. This was well highlighted by the peak of the hsCRP when referred to its CDV (Figs. 1 and 2); the contemporary invariance of IL-6 levels could have depended from the dual role of this cytokine, both pro- and anti-inflammatory, but it cannot be excluded that it could have depended from the poor sensitivity of the analysis method employed.

The consequent homeostatic unbalance has been showed at V3, in which dROMs increased and GSH decreased for greater consumption; hsCRP was elevated while BAP remained still well represented, probably because supported by the antioxidant dietary intake.

When the balance is altered and the oxinflammation triggered, the vicious circle between productions of inflammatory cytokines and free radicals feeds itself, with oxidations that cause inflammations and consumptions of antioxidant barrier, until appearance of irreversible oxidative alterations on macromolecules at different cellular levels. In these conditions, the measurement of redox damage biomarkers, such as 3-NT and 8-OHdG, becomes necessary $[63,64]$.

In our study, the 3-NT levels, which remained under the upper limit of reference range (ULRR) up to V2 [65], were much increased in V3 and V4, showing that the impairment of redox equilibrium had caused, by now, irreversible nitrations on the protein compartment.

To enhance the glutathione synthesis and thus support the endogenous antioxidant barrier, the administration of hypotonic solutions of maltodextrin during training sessions starting from V3 has proved effective in V4, with weak improvements in total and reduced glutathione concentrations (Fig. 2). Also, hsCRP had appeared slightly lower in V4 than in previous visits, while dROMs were in further slight increase and the exogenous antioxidant barrier in decrease; compared to V3, plasma concentrations of vitamins $\mathrm{A}, \mathrm{E}$ and lycopene in $\mathrm{V} 4$ were lowering $(-33 \%,-10 \%$, and $-23 \%$, respectively). To confirm the redox balance impairment, 3-NT has increased in V4 more than ten times versus V3, well beyond its CDV. Instead $80 \mathrm{HdG}$, despite the apparent variations between V1 and V4, never exceeded the ULRR, and therefore did not allow demonstrate the presence of oxidative damage on nucleobases [65].

The alteration of redox balance consequent to the increase in high-intensity training starting from
V2 [66-68], highlighted that the amount of eccentric component of activity must be always taken into serious account in the programming $[69,70]$, even considering the little improvement of the anabolic ratio (T/C) obtained. Moreover, in the past the usefulness of the $\mathrm{T} / \mathrm{C}$ index had been already criticized, because influenced by study design and time of sampling $[71,72]$. The ineffectiveness of this parameter seemed to emerge even from our data in which, despite of a sharp oxinflammatory imbalance, weak increases were seen in T/C between V2 and V3 only $(+21 \%)$, and returns at pre-season values in V4.

However, because it has already been shown that the effects of training on the match-performances and $\mathrm{T} / \mathrm{C}$ ratio were related to the position of soccer players in the field [73], further studies will be undertaken to verify if this is true also for the oxyinflammation biomarkers. For the moment, we can only observe that the worsening of the redox state has overlapped, with a certain coincidence of time, to a sharp deterioration in match-performances of the team in the second half of season.

\section{Conclusions}

The control of nutrition and training of athletes can ensure the maintenance of balanced conditions in which pro-inflammatory and pro-oxidative stimulations only transiently alters the oxinflammatory homeostasis and trigger the enhancement of counter-regulatory response.

High-intensity work increases the nutritional demand, and may induce muscle damage, inflammation and oxidative stress. Moreover, above a certain threshold, the eccentric exercise does not improve the anabolic ratio and alters the oxinflammatory balance.

The nutritional intervention may act on the strengthening of the antioxidant barrier and allows to partially counteract the alterations. Nevertheless, the worsening of the homeostasis and of the performances of team at the end of season showed that the oxinflammatory balance is probably conditioned in a more relevant way by the training overload.

A more closed collaboration between physicians, nutritionists, and athletic trainers is of crucial importance in order to identify for each athlete, the exact balance between training, rest and nutrition, in order to optimize his athletic performance.

It is suggestive to think that, alongside the necessary customization of interventions for each player, the measurement of some biochemical markers of oxinflammation, such as hsCRP, glutathione, and 
3-NT, can be a useful tool to identify conditions of overstrain and to prevent the approach of the over-training threshold.

\section{Acknowledgments}

The Authors would like to thank Alberto Botter to have provided the data for training load quantification, and the company Udinese calcio Spa for its technical support, and above all, its effort and constant encouragement to combine science and sport.

\section{Conflict of interests}

The authors declare that they have no conflict of interest with the topics discussed and that the study was completely self-financed without intervention of pharmaceutical companies or any other sponsor. This manuscript has been read and approved by all the authors; each author declares that the manuscript represents an original work never previously published either in whole or in part.

\section{References}

[1] Fisher-Wellman K, Bloomer RJ. Acute exercise and oxidative stress: a 30 years history. Dyn Med 2009; $8: 1-25$.

[2] Souglis A, Bogdanis GC, Chryssanthopoulos C, Apostolidis N, Geladas ND. Time course of oxidative stress, inflammation and muscle damage markers for five days after a soccer match: effects of sex and playing position. J Strenght Cond Res 2018; 32(7):1-10.

[3] Benedetti S, Catalani S, Peda F, Luchetti F, Citarella $\mathrm{R}$, Battistelli S. Impact of the 24-h ultramarathon race on homocysteine, oxidized low-density lipoprotein, and paraoxonase 1 levels in professional runners. PLoS One 2018; 13(2):e0192392.

[4] Barros ES, Nascimento DC, Prestes J, Nobrega OT, Cordova C, Sousa F, et al. Acute and chronic effects of endurance running on inflammatory markers: a systematic review. Front Physiol 2017; 8:779.

[5] Spanidis Y, Stagos D, Papanikolaou C, Karatza K, Theodosi A, Veskoukis A, et al. Resistance-trained individuals are less susceptible to oxidative damage after eccentric exercise. Oxid Med Cell Longev 2018; doi.org/10.1155/2018/6857190

[6] Barbieri E, Sestili P. Reactive oxygen species in skeletal muscle signaling. J Signal Transduct 2012; doi:10.1155/2012/982794

[7] Brigelius-Flohé R, Flohé L. Basic principles and emerging concepts in the redox control of transcription factors. Antioxid Redox Signal 2011; 15:2335-81.

[8] Couto Gomes E, Nunes Silva A, Rubino de Oliveira M. Oxidants, antioxidants, and the beneficial roles of exercise-induced production of reactive species. Oxid Med Cell Longev 2012; doi:10.1155/2012/756132

[9] Feinberg AP, Fallin MD. Epigenetics at the crossroads of genes and the environment. JAMA 2015; 314(11):1129-30.

[10] Webb R, Hughes MG, Thomas AW, Morris K. The ability of exercise-associated oxidative stress to trigger redox-sensitive signalling responses. Antioxidants 2017; 6:63.

[11] Antunes BM, Campos EZ, Dos Santos RVT, RosaNeto JC, Franchini E, Bishop NC, et al. Antiinflammatory response to acute exercise is related with intensity and physical fitness. J Cell Biochem 2018; doi:10.1002/jcb.27810

[12] Cobley JN, Margaritelis NV, Morton JP, Close GL, Nikolaidis MG, Malone JK. The basic chemistry of exercise-induced DNA oxidation: oxidative damage, redox signaling, and their interplay. Front Physiol 2015; 6:182.

[13] Lugrin J, Rosenblatt-Velin N, Parapanov R, Liaudet L. The role of oxidative stress during inflammatory process. Biol Chem 2014; 395(2):203-30.

[14] Lingappan K. NF-kB in oxidative stress. Curr Opin Toxicol 2018; 7:81-6.

[15] Speer K, Upton D, Semple S, McKune A. Systemic low-grade inflammation in post-traumatic stress disorder: a systematic review. J Inflamm Res 2018; 11:111-21.

[16] Valacchi G, Virgili F, Cervellati C, Pecorelli A. OxInflammation: from subclinical condition to pathological biomarker. Front Physiol 2018; 9:858.

[17] Tanskanen M, Atalay M, Uusitalo A. Altered oxidative stress in overtrained athletes. J Sport Sci 2010; 28(3):309-17.

[18] Pereira BC, Pauli JR, Antunes LM, De Freitas EC, De Almeida MR, De Paula Venancio V, et al. Overtraining is associated with DNA damage in blood and skeletal muscle cells of Swiss mice. BMC Physiol 2013; 13:11.

[19] Jin CH, Paik IY, Kwak YS, Jee YS, Kim JY. Exhaustive submaximal endurance and resistance exercises induce temporary immunosuppression via physical and oxidative stress. J Exerc Rehabil 2015; 11(4):198-203.

[20] Lewis NA, Redgrave A, Homer M, Burden R, Martinson W, Moore B, et al. Alterations in redox homeostasis during recovery from unexplained underperformance syndrome in an elite international rower. Int J Sports Physiol Perform 2018; 13(1):107-11.

[21] Biolo G, Di Girolamo FG, Fiotti N, Mearelli F, Sarto P. Exercise-mediated reactive oxygen species generation in athletes and in patients with chronic disease. Intern Emerg Med 2017; 12(6):741-44.

[22] Dupuy O, Douzi W, Theurot D, Bosquet L, Dugué B. An evidence-based approach for choosing post-exercise recovery techniques to reduce markers of muscle damage, soreness, fatigue, and inflammation: 
a systematic review with meta-analysis. Front Physiol 2018; doi:10.3389/fphys.2018.00403

[23] Theofilidis G, Bogdanis GC, Koutedakis Y, Karatzaferi C. Monitoring exercise-induced muscle fatigue and adaptations: making sense of popular or emerging indices and biomarkers. Sports 2018; 6:153.

[24] Bjork L, Jenkins NT, Witkowski S, Hagberg JM. Nitrooxidative stress-biomarkers in active and inactive men. Int J Sports Med 2012; 33(4):279-84.

[25] Martinović J, Dopsaj V, Kotur-Stevuljević J, Dopsaj M, Vujović A, Stefanović, A, Nešić G. Oxidative stress biomarker monitoring in elite women volleyball athletes during a 6-week training period. J Strength Cond Res 2011; 25(5):1360-7.

[26] Lee EC, Fragala MS, Kavouras SA, Queen RM, Pryor JL, Casa DJ. Biomarkers in sports and exercise: tracking health, performance, and recovery in athletes. J Strength Cond Res 2017; 31(10):2920-37.

[27] Young JI, Züchner S, Wang G. Regulation of the epigenome by vitamin C. Annu Rev Nutr 2015; 35:545-64.

[28] Kurutas EB. The importance of antioxidants which play the role in cellular response against oxidative/ nitrosative stress: current state. Nutr J 2016; 15:71.

[29] Saraiva Anjos J, Cardozo L, Esgalhado M, Lindholm B, Stenvinkel P, Fouque D, Mafra D. Could low-protein diet modulate Nrf2 pathway in chronic kidney disease? J Renal Nutr 2017; 28(4):229-34.

[30] Shivappa N, Herbert JR, Marcos A, Diaz LE, Gomez S, Nova E, et al. Association between dietary inflammatory index and inflammatory markers in the HELENA study. Mol Nutr Food Res 2017; doi:10.1002/mnfr.201600707

[31] Della Corte KW, Perrar I, Penczynski KJ, Schwingshackl L, Herder C, Buyken AE. Effect of dietary sugar intake on biomarkers of subclinical inflammation: a systematic review and meta-analysis of intervention studies. Nutrients 2018; doi:10.3390/nu10050606

[32] Innes JK, Calder PC. Omega- 6 fatty acids and inflammation. PLEFA 2018; 132:41-8.

[33] Lam J, McKeague M. Dietary modulation of mitochondrial DNA damage: implications in aging and associated diseases. J Nutr Biochem 2019; 63:1-10.

[34] Maso F, Lac G, Filaire E, Michaux 0, Robert A. Salivary testosterone and cortisol in rugby players: correlation with psychological overtraining items. Br J Sports Med 2004; 38:260-63.

[35] Ferreri C, Masi A, Sansone A, Giacometti G, Larocca $\mathrm{AV}$, Menounou G, et al. Fatty acids in membranes as homeostatic, metabolic, and nutritional biomarkers: recent advancements in analytics and diagnostics. Diagnostics 2017; doi:10.3390/ diagnostics7010001

[36] Bolner A, Pilleri M, De Riva V, Nordera GP. Plasmatic and urinary HPLC-ED determination of the ratio 8-OHdG/2-dG in Parkinson's disease. Clin Lab 2011; 57(11-12):859-66.
[37] Hillman AR, Vince RV, Taylor LA, Mcnaughton LR, Mitchell N, Siegler JC. Exercise-induced dehydration with and without environmental heat stress results in increased oxidative stress. Appl Physiol Nutr Metab 2011; doi:10.1139/h11-080

[38] King MA, Clanton TL and Laitano O. Hyperthermia, dehydration, and osmotic stress: unconventional sources of exercise-induced reactive oxygen species. Am J Physiol Regul Integr Comp Physiol 2016; 310:R105-14.

[39] O’Brien C, Young AJ, Sawka MN. Bioelectrical impedance to estimate changes in hydration status. Int J Sports Med 2002; 23:361-66.

[40] Matias CN, Santos D, Júdice PB, Magalhães JP, Minderico CS, Fields DA, et al. Estimation of total body water and extracellular water with bioimpedance in athletes: a need for athlete-specific prediction models. Clin Nutr 2016; 35(2):468-74.

[41] Kushner RF, Schoeller DA. Estimation of total body water by bioelectrical impedance analysis. Am J Clin Nutr 1986; 44:417-24.

[42] Castizo-Olier J, Irurtia A, Jemni M, CarrascoMarginet $M$, Fernandez-Garcìa $R$, Rodrìguez FA. Bioelectrical impedance vector analysis (BIVA) in sport and exercise: systematic review and future perspectives. PLoS One 2018; 13(6):e0197957.

[43] Ravussin E, Bogardus C. Relationship of genetics, age, and physical fitness to daily energy expenditure and fuel utilization. Am J Clin Nutr 1989; 49(5 Suppl):968-75.

[44] Lukaski HC, Bolonchuk WW, Siders WA, Hall CB. Body composition assessment of athletes using bioelectrical impedance measurements. J Sports Med Phys Fitness 1990; 30(4):434-40.

[45] Brinkmans NYJ, Iedema N, Plasqui G, Wouters L, Saris WHM, van Loon LJC, et al. Energy expenditure and dietary intake in professional football players in the Dutch Premier League: implications for nutritional counselling. J Sports Sci 2019; 16:1-9.

[46] Wong SH, Williams C. Effects of ingesting a large volume of carbohydrate-electrolyte solution on rehydration during recovery and subsequent exercise capacity. Int J Sport Med 2000; 21:444-52.

[47] Hodgson C, Akenhead R, Thomas K. Time-motion analysis of acceleration demands of $4 \mathrm{v} 4$ smallsided soccer games played on different pitch sizes. Hum Movement Sci 2014; 33:25-32.

[48] Osgnach C, Poser S, Bernardini R, Rinaldo R, Di Prampero PE. Energy cost and metabolic power in elite soccer: a new match analysis approach. Med Sci Sports Exerc 2010; 42(1):170-8.

[49] Fraser CG. Biological variation: from principles to practice. AACC Press, Washington, DC, 2001.

[50] Fraser CG. Reference change values. Clin Chem Lab Med 2011; 50(5):807-12.

[51] Lewis NA, Newell J, Burden R, Howatson G, Pedlar CR. Critical difference and biological variation in biomarkers of oxidative stress and nutritional status in athletes. PLoS One 2016; 11(3):e0149927. 
[52] Jones DP. Radical-free biology of oxidative stress. Am J Physiol Cell Physiol 2008; 295:839-68.

[53] Atkins P, De Paula J. Atkins' physical chemistry. 9th edition, OUP Oxford, UK, 2009.

[54] Rogers LK, Moorthy B. Role of reactive oxygen species (ROS) in health and disease: mechanisms, target organ toxicities, and biomarkers. Curr Opin Toxicol 2018; 7:i-iii.

[55] Sies H. On the history of oxidative stress: concept and some aspects of current development. Curr Opin Toxicol 2018; 7:122-26.

[56] Michailidis Y, Jamurtas MG, Nikolaidis MG. Sampling time is crucial for measurement of aerobic exercise-induced oxidative stress. Med Sci Sports Exerc 2007; 39(7):1107-13.

[57] Folchetti LD, Monfort-Pires M, deBarros CR, Martini LA, Ferreira RG. Association of fruits and vegetables consumption and related-vitamins with inflammatory and oxidative stress markers in prediabetic individuals. Diabetol Metab Syndr 2014; 6:22-9.

[58] Kurutas EB. The importance of antioxidants which play the role in cellular response against oxidative/nitrosative stress: current state. Nutr J 2016; 15:71-92.

[59] Minuz P, Velo G, Violi F, Ferro A. Are nutraceuticals the modern panacea? From myth to science. Br J Clin Pharmacol 2017; 83:5-7.

[60] Borghi C, Cicero AFG. Nutraceuticals with a clinically detectable blood pressure-lowering effect: a review of available randomized clinical trials and their meta-analyses. Br J Clin Pharmacol 2018; 3:163-71.

[61] Von Shacky C, Kemper M, Halsbauer and Halle M. Low omeg-3 index in 106 german elite winter endurance athletes: a pilot study. Int J Sport Nutr Exerc Metab 2014; 24(5):559-64.

[62] Tepsic J, Vucic V, Arsic A, Blazencic-Mladenovic A, Mazic S, Glibetic M. Plasma and erythrocyte phospholipid fatty acid profile in professional basketball and football players. Eur J Appl Physiol 2009; 107:359-65.

[63] Bolner A, D’Andrea G, Bosello O, Nordera GP. Oxidative stress in chronic headaches: old and new markers. OAMS 2015; 4(3):119-24.
[64] Bolner A, Pilleri M, Bosello O, Nordera GP. Oxidative damage on nucleobases and Hoehn-Yahr stage in Parkinson's disease. Am J Res Med Sci 2018; 3(2):36-47.

[65] Bolner A, Micciolo R, Bosello O, Nordera GP. A panel of oxidative stress markers in Parkinson's disease. Clin Lab 2016; 62:105-12.

[66] Paschalis V, Nikolaidis MG, Fatouros IG, Giakas G, Koutedakis Y, Karatzaferi C, et al. Uniform and prolonged changes in blood oxidative stress after muscle-damaging exercise. In Vivo 2007; 21(5):877-84.

[67] Fatouros IG, Chatzinikolaou A, Douroudos II, Nikolaidis MG, Kyparos A, Margonis K. Time-course of changes in oxidative stress and antioxidant status responses following a soccer game. J Strenght Cond Res 2010; 24:3278-86.

[68] Silva JR, Ascensao A, Marques F, Seabra A, Rebelo A, Magalhaes J. Neuromuscular function, hormonal and redox status and muscle damage of profesisonal soccer players after a high-level competitive match. Eur J Appl Physiol 2013; 113:2193-201.

[69] Paschalis V, Nikolaidis MG, Fatouros IG, Giakas G, Koutedakis Y, Karatzaferi C, et al. Uniform and prolonged changes in blood oxidative stress after muscle-damaging exercise. In Vivo 2007; 21:877-83.

[70] Theodorou AA, Nikolaidis MG, Paschalis V, Koutsias S, Panayiotou G, Fatouros IG, et al. No effect of antioxidant supplementation on muscle performance and blood redox status adaptations to eccentric training. Am J Clin Nutr 2011; 93:1373-83.

[71] Hayes LD, Grace FM, Baker JS, Sculthorpe N. Exercise-induced responses in salivary testosterone, cortisol, and their ratios in men: a meta-analysis. Sports Med 2015; 45(5):713-26.

[72] Filaire E, Bernain X, Sagnol M, Lac G. Preliminary results on mood state, salivary testosterone: cortisol ratio and team performance in a professional soccer team. Eur J Appl Physiol 2001; 86(2):179-84.

[73] Rowell AE, Aughey RJ, Hopkins WG, Esmaeili A, Lazarus BH, Cormack SJ. Effects of training and competition load on neuromuscular recovery, testosterone, cortisol, and match performance during a season of professional football. Front Physiol 2018; doi: 10.3389/fphys.2018.00668 